\title{
5th Russian Conference on Medicinal Chemistry with international participation MedChem-Russia 2021
}

The 5th Russian Conference on Medicinal Chemistry with international participation, MedChem-Russia, will be held at the Volgograd State Medical University (October 5-6, 2021) and the Volgograd State Technical University (October $7-8,2021)$. The Conference is organized under the aegis of the European Federation for Medicinal Chemistry.

\section{Organizers}

Ministry of Science and Higher Education of the Russian Federation

Russian Academy of Sciences (RAS)

Division of Chemistry and Materials Sciences of the RAS

Scientific Council on Medicinal Chemistry of the RAS

Division for Medicine of the RAS

Ministry of Health of the Russian Federation

Administration of the Volgograd Region

Russian Foundation for Basic Research

Volgograd State Medical University (VolgSMU)

Volgograd State Technical University (VolgSTU)

Faculty of Chemistry, M. V. Lomonosov Moscow State University

Institute of the Physiologically Active Substances of the RAS

I. Ya. Postovsky Institute of Organic Synthesis, Ural Branch of the RAS

D. I. Mendeleev Russian Chemical Society, Section of Medicinal Chemistry

International Public Organization "Association of Clinical Pharmacologists"

Presidents of the Conference Chairmen of the Conference

Co-chairmen

Chairmen

Scientific Secretary

Deputy Scientific Secretary
Academicians of the RAS V. I. Petrov and V. N. Charushin

Corresponding Member of the RAS S. O. Bachurin, V. V. Shkarin (Chancellor of the VolgSMU), and A. V. Navrotskii (Chancellor of the VolgSTU)

Organizing Committee

Academician of the RAS A. A. Spasov and Professor S. V. Kuzmin

Program Committee

Academicians of the RAS A. A. Spasov, I. A. Novakov, and O. N. Chupakhin, and Corresponding Member of the RAS S. O. Bachurin

Professor O. N. Zefirova

Professors Yu. L. Zotov and V. A. Kosolapov

\section{Program of the Conference}

- New synthetic approaches in medicinal chemistry

- Target-based drug design

- Scientific and methodical grounds for the search and development of new drugs

- Medicinal bioinorganic chemistry

- Radiopharmaceuticals

- Search for new drugs based on natural compounds

- Computer design of new drugs

- Biotechnological aspects of medicinal chemistry

- Current issues of pilot and industrial production of pharmaceutical substances.

- Pharmaceutical aspects of medicinal chemistry (development of dosage forms and drug manufacture).

- Search and development of new antiviral drugs (including COVID-19 infection).

The scientific program includes plenary lectures, reports of top specialists, oral reports, two poster sessions, and two round tables "Educational programs in medicinal and pharmaceutical chemistry" and "Ways for accelerating the practical implementation of innovative pharmaceutical products.

The Conference will host the Satellite Youth Symposium for Undergraduate and Postgraduate Students, which includes oral reports $(10-15 \mathrm{~min})$ and posters.

Contacts: E-mail: medchemvolga21@gmail.com

Scientific Secretary and Deputies: Ol'ga Nikolaevna Zefirova, phone.: +7 (495) 9391243 ;

Yurii L'vovich Zotov, phone.: +7 (8442) 24 8078; Vadim Anatol'evich Kosolapov, phone: +7 (8442) 975105. 